\title{
Six New Acylated Anthocyanins from Red Radish (Raphanus sativus)
}

\author{
Satoru Tamura, ${ }^{a}$ Kouji Tsums, ${ }^{a}$ Piao Yongzhen, ${ }^{a}$ Mayumi Ohnishi-Kameyama, ${ }^{b}$ and \\ Nobutoshi MuraKami ${ }^{*, a}$ \\ ${ }^{a}$ Graduate School of Pharmaceutical Sciences, Osaka University; 1-6 Yamada-oka, Suita, Osaka 565-0871, Japan: and \\ ${ }^{b}$ National Food Research Institute, Ministry of Agriculture, Forestry and Fishers; 2-1-12 Kannondai, Tsukuba, Ibaraki \\ 305-8642, Japan. Received May 12, 2010; accepted June 4, 2010; published online June 8, 2010
}

Six new acylated anthocyanins (1-6) were isolated along with the three known congeners (7-9) from the fresh roots of red radishes (Raphanus sativus $\mathrm{L}$.) cultivated by our group. Their chemical structures were elucidated by spectroscopic properties. Among the six new anthocyanins, the five constituents $(1,2,4-6)$ were shown to contain the malonyl function at $6-\mathrm{OH}$ in the glucopyranosyl residue linked to $\mathrm{C}-5$ in the pelargonidin nucleus.

Key words anthocyanin; red radish; Raphanus sativus; pelargonidin; malonyl group

Anthocyanins are natural pigments belonging to the flavonoid family and responsible for the blue, purple, red, and orange colors of many fruits and vegetables. Recently, interest in anthocyanins has significantly increased due to not only their wide use as natural alternatives to artificial colorants but also implication of potential health benefits. ${ }^{1)}$ With respect to edible plant resources, purple corn, ${ }^{2)}$ red cabbages,${ }^{3)}$ purple sweet potatoes, ${ }^{4-6)}$ blueberries, ${ }^{7)}$ elderberries, ${ }^{8,9)}$ and red radishes ${ }^{10-12)}$ were found to contain anthocyanins in high content so far. Among them, anthocyanins in the red radishes are distinguished from those in the other plants by the structure of the aglycon; the formers and the latters contain pelargonidin and cyanidin as aglycons, respectively. Due to this structural feature, the red radish anthocyanins bring about characteristic coloration different from the cyanidin-based anthocyanins. ${ }^{13)}$ Moreover, only the red radish anthocyanins have been widely used as natural colorants comprised of pelargonidin-based anthocyanins so far. In this context, the red radishes should be regarded as important resources of natural colorants with seasoned safety.

As a part of our scientific investigation on cultivation of the red radishes, ${ }^{14)}$ we examined the anthocyanin ingredients from the plant materials cultivated by us. Consequently, we have isolated six new acylated anthocyanins $(\mathbf{1}-\mathbf{6})$ together with the three known congeners (7-9). Here, we describe the structural elucidation of these new anthocyanins from the fresh roots of red radishes (Fig. 1).
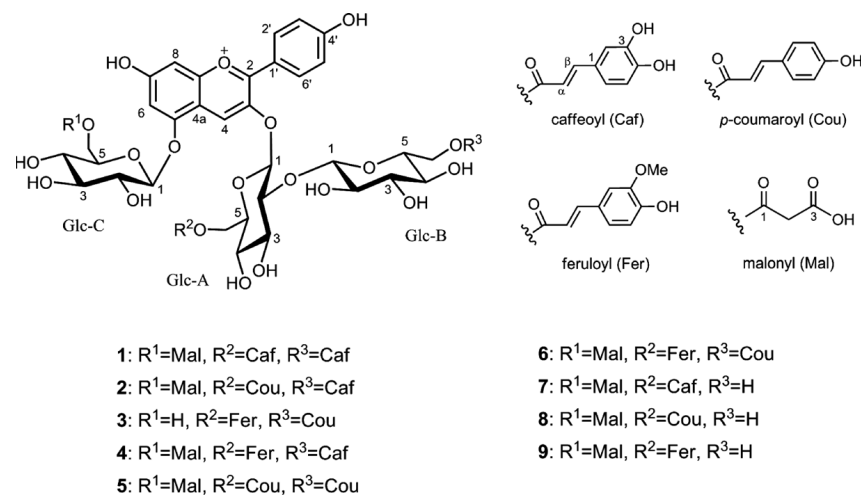

6: $R^{1}=$ Mal, $R^{2}=F e r, R^{3}=$ Cou

7: $\mathrm{R}^{1}=\mathrm{Mal}, \mathrm{R}^{2}=$ Caf, $\mathrm{R}^{3}=\mathrm{H}$

8: $R^{1}=M a l, R^{2}=\mathrm{Cou}, R^{3}=\mathrm{H}$

9: $\mathrm{R}^{1}=$ Mal, $\mathrm{R}^{2}=$ Fer, $\mathrm{R}^{3}=\mathrm{H}$

Fig. 1. Chemical Structures of Anthocyanins (1-9) from Raphanus sativus $\mathrm{L}$.

\section{Results and Discussion}

After the fresh roots of the red radishes were extracted with 5\% aqueous citric acid, the resulting extract was subjected to Diaion HP-20 column chromatography to afford a crude mixture of anthocyanins. Separation of the mixture by reversed-phase HPLC furnished the six new anthocyanins (1-6) along with the three known congeners (7-9). ${ }^{11,15)}$ The FAB-MS of $1(0.015 \%$ from the roots) showed the molecular ion peak at $1167[\mathrm{M}]^{+}$and the molecular formula $\mathrm{C}_{54} \mathrm{H}_{55} \mathrm{O}_{29}$ of 1 was determined by the high resolution (HR)FAB-MS ([M $]^{+} m / z$ 1167.2826, Calcd 1167.2829). The IR absorptions at $3300,1718(\mathrm{sh}), 1685$, and $1641 \mathrm{~cm}^{-1}$ indicated the presence of hydroxyl, carbonyl, and $\alpha, \beta$-unsaturated enone functionalities, respectively. The ${ }^{1} \mathrm{H}-\mathrm{NMR}$ spectrum showed the signals due to the 1,2,3,5-tetrasubstituted aromatic ring $\left[\delta_{\mathrm{H}} 6.96(\mathrm{H}-8, \mathrm{~s}), 6.91(\mathrm{H}-6, \mathrm{~s})\right]$, the 1,4-disubstituted aromatic ring $\left[\delta_{\mathrm{H}} 8.50\left(\mathrm{H}-2^{\prime}, 6^{\prime}, \mathrm{d}, J=8.9 \mathrm{~Hz}\right), 7.01\right.$ $\left.\left(\mathrm{H}-3^{\prime}, 5^{\prime}, \mathrm{d}, J=8.9 \mathrm{~Hz}\right)\right]$, and the three anomeric protons $\left[\delta_{\mathrm{H}}\right.$ $5.54(\mathrm{H}-1$ in Glc-A, d, $J=7.6 \mathrm{~Hz}), 5.11(\mathrm{H}-1$ in Glc-C, d, $J=7.6 \mathrm{~Hz}), 4.77$ (H-1 in Glc-B, d, $J=7.6 \mathrm{~Hz}$ )] along with the low-field singlet signal $\left[\delta_{\mathrm{H}} 8.85(\mathrm{H}-4, \mathrm{~s})\right]$ characteristic of the anthocyanidin skeleton (Table 1). Furthermore, the ${ }^{13} \mathrm{C}-\mathrm{NMR}$ spectrum indicated the signals ascribable to the three anomeric carbons $\left[\delta_{\mathrm{C}} 104.5\right.$ (C-1 in Glc-B), 101.7 (C-1 in Glc-C), 100.4 (C-1 in Glc-A)] (Table 2).

A combination of the $\mathrm{H}-\mathrm{H}$ correlation spectroscopy (COSY), heteronuclear multiple quantum coherence (HMQC), and heteronuclear multiple bond connectivity (HMBC) experiments allowed unambiguous assignments of all proton and carbon signals of $\mathbf{1}$ to disclose the presence of three sugar residues and three acyl groups. Based on the chemical shifts as well as the coupling constants of the proton signals in the sugar moieties of $\mathbf{1}$, all of the three sugar portions were deduced to be $\beta$-D-glucopyranosyl residues. With respect to the acyl groups, the presence of the malonyl (Mal) function $\left[\delta_{\mathrm{H}} 3.32\left(\mathrm{H}-2\right.\right.$ in Mal, s), $\delta_{\mathrm{C}} 166.9(\mathrm{C}-1$ in Mal), 41.7 (C-2 in Mal), 167.7 (C-3 in Mal)] was revealed together with the two $(E)$-caffeoyl $(\mathrm{Caf})$ functions $\left[\delta_{\mathrm{H}} 7.25\right.$ $(\beta-\mathrm{H}, \mathrm{d}, J=15.8 \mathrm{~Hz}), 7.14(\beta-\mathrm{H}, \mathrm{d}, J=15.8 \mathrm{~Hz}), 6.07(\alpha-\mathrm{H}, \mathrm{d}$, $J=15.8 \mathrm{~Hz}), 5.87(\alpha-\mathrm{H}, \mathrm{d}, J=15.8 \mathrm{~Hz}), \delta_{\mathrm{C}} 166.9,166.7(\mathrm{CO}$ in $\mathrm{Caf}$ ), $145.8,145.5$ ( $\beta$-C in Caf), 114.0, $114.0(\alpha-\mathrm{C}$ in Caf)].

Location of the sugar residues and the acyl groups was definitely determined by the HMBC technique. In brief, the 
Table 1. ${ }^{1} \mathrm{H}-\mathrm{NMR}$ Data for Anthocyanins $\mathbf{1}-\mathbf{6}\left(600 \mathrm{MHz}, \mathrm{DMSO}-d_{6}: \mathrm{CF}_{3} \mathrm{COOD}=9: 1\right)$

\begin{tabular}{|c|c|c|c|c|c|c|}
\hline Proton & 1 & 2 & 3 & 4 & 5 & 6 \\
\hline \multicolumn{7}{|l|}{ Aglycon } \\
\hline 4 & $8.85 \mathrm{~s}$ & $8.81 \mathrm{~s}$ & $8.86 \mathrm{~s}$ & $8.85 \mathrm{~s}$ & $8.82 \mathrm{~s}$ & $8.86 \mathrm{~s}$ \\
\hline 6 & $6.91 \mathrm{~s}$ & $6.90 \mathrm{~s}$ & $6.87 \mathrm{~s}$ & $6.89 \mathrm{~s}$ & $6.89 \mathrm{~s}$ & $6.90 \mathrm{~s}$ \\
\hline 8 & $6.96 \mathrm{~s}$ & $6.96 \mathrm{~s}$ & $6.92 \mathrm{~s}$ & $6.97 \mathrm{~s}$ & $6.94 \mathrm{~s}$ & $6.97 \mathrm{~s}$ \\
\hline $2^{\prime}, 6^{\prime}$ & $8.50 \mathrm{~d}(8.9)$ & $8.50 \mathrm{~d}(8.9)$ & $8.50 \mathrm{~d}(8.9)$ & $8.51 \mathrm{~d}(8.9)$ & 8.50 d (8.9) & $8.51 \mathrm{~d}(8.9)$ \\
\hline $3^{\prime}, 5^{\prime}$ & $7.01 \mathrm{~d}(8.9)$ & $7.02 \mathrm{~d}(8.9)$ & $7.01 \mathrm{~d}(8.9)$ & $7.03 \mathrm{~d}(8.9)$ & $7.01 \mathrm{~d}(8.9)$ & $7.02 \mathrm{~d}(8.9)$ \\
\hline \multicolumn{7}{|l|}{ Glc-A } \\
\hline 1 & $5.54 \mathrm{~d}(7.6)$ & $5.57 \mathrm{~d}(6.9)$ & $5.51 \mathrm{~d}(7.6)$ & $5.56 \mathrm{~d}(7.6)$ & $5.53 \mathrm{~d}(7.6)$ & $5.53 \mathrm{~d}(7.6)$ \\
\hline 2 & 3.93 dd $(7.6,8.9)$ & $3.95 \mathrm{dd}(6.9,8.2)$ & $3.91 \mathrm{dd}(7.6,8.9)$ & 3.94 dd $(7.6,8.9)$ & $3.93 \mathrm{dd}(7.6,8.2)$ & $3.92 \mathrm{dd}(7.6,8.2)$ \\
\hline 3 & $3.67 \mathrm{dd}(8.9,8.9)$ & $3.68 \mathrm{dd}(8.2,8.2)$ & $3.67 \mathrm{dd}(8.9,8.9)$ & $3.68 \mathrm{dd}(8.9,8.9)$ & $3.68 \mathrm{dd}(8.2,8.2)$ & $3.65 \mathrm{dd}(8.2,8.3)$ \\
\hline 4 & $3.40 \mathrm{dd}(8.9,8.9)$ & $3.37 \mathrm{~m}$ & $3.45 \mathrm{~m}$ & $3.41 \mathrm{dd}(8.9,8.9)$ & $3.37 \mathrm{dd}(8.2,8.9)$ & $3.38 \mathrm{~m}$ \\
\hline 5 & $3.82 \mathrm{~m}$ & $3.86 \mathrm{~m}$ & $3.80 \mathrm{~m}$ & $3.86 \mathrm{~m}$ & $3.82 \mathrm{~m}$ & $3.82 \mathrm{~m}$ \\
\hline $6 a$ & 4.36 br d (11.0) & 4.34 br d (11.0) & $4.36 \mathrm{~m}$ & 4.39 br d (12.4) & 4.35 br d (11.3) & 4.36 br d (12.0) \\
\hline $6 b$ & $4.20 \mathrm{dd}(6.2,11.0)$ & $4.19 \mathrm{dd}(7.6,11.0)$ & $4.23 \mathrm{~m}$ & $4.18 \mathrm{dd}(6.9,12.4)$ & 4.19 dd $(6.8,11.3)$ & $4.16 \mathrm{dd}(6.9,12.0)$ \\
\hline \multicolumn{7}{|l|}{ Glc-B } \\
\hline 1 & $4.77 \mathrm{~d}(7.6)$ & $4.79 \mathrm{~d}(7.6)$ & $4.78 \mathrm{~d}(8.2)$ & $4.80 \mathrm{~d}(8.2)$ & $4.79 \mathrm{~d}(7.6)$ & $4.80 \mathrm{~d}(8.2)$ \\
\hline 2 & $3.09 \mathrm{~m}$ & $3.07 \mathrm{~m}$ & 3.09 dd $(8.2,8.9)$ & $3.08 \mathrm{~m}$ & $3.07 \mathrm{dd}(7.6,8.2)$ & $3.07 \mathrm{~m}$ \\
\hline 3 & $3.22 \mathrm{ol}^{a)}$ & $3.20 \mathrm{ol}$ & $3.23 \mathrm{ol}$ & $3.23 \mathrm{ol}$ & $3.23 \mathrm{ol}$ & $3.21 \mathrm{ol}$ \\
\hline 4 & $3.22 \mathrm{ol}$ & $3.20 \mathrm{ol}$ & $3.21 \mathrm{~m}$ & $3.32 \mathrm{ol}$ & $3.29 \mathrm{ol}$ & $3.31 \mathrm{ol}$ \\
\hline 5 & $3.22 \mathrm{ol}$ & $3.20 \mathrm{ol}$ & $3.23 \mathrm{ol}$ & $3.22 \mathrm{ol}$ & $3.23 \mathrm{ol}$ & $3.21 \mathrm{ol}$ \\
\hline $6 a$ & $4.02 \mathrm{~m}$ & $4.01 \mathrm{~m}$ & 4.07 br d (10.3) & $4.03 \mathrm{~m}$ & $4.04 \mathrm{~m}$ & $4.04 \mathrm{~m}$ \\
\hline $6 b$ & $3.99 \mathrm{~m}$ & $4.01 \mathrm{~m}$ & $4.00 \mathrm{~m}$ & $4.01 \mathrm{~m}$ & $4.00 \mathrm{~m}$ & $3.98 \mathrm{~m}$ \\
\hline \multicolumn{7}{|l|}{ Glc-C } \\
\hline 1 & $5.11 \mathrm{~d}(7.6)$ & $5.10 \mathrm{~d}(7.6)$ & $5.02 \mathrm{~d}(7.6)$ & $5.10 \mathrm{~d}(7.6)$ & $5.08 \mathrm{~d}(7.6)$ & $5.09 \mathrm{~d}(8.2)$ \\
\hline 2 & $3.50 \mathrm{dd}(7.6,8.9)$ & $3.50 \mathrm{dd}(7.6,8.9)$ & $3.45 \mathrm{dd}(7.6,8.9)$ & $3.48 \mathrm{dd}(7.6,8.9)$ & $3.50 \mathrm{dd}(7.6,8.9)$ & $3.46 \mathrm{dd}(8.2,8.4)$ \\
\hline 3 & 3.36 dd $(8.9,8.9)$ & $3.35 \mathrm{dd}(8.9,8.9)$ & $3.33 \mathrm{dd}(8.9,8.9)$ & $3.35 \mathrm{dd}(8.9,8.9)$ & $3.35 \mathrm{dd}(8.9,8.9)$ & $3.33 \mathrm{~m}$ \\
\hline 4 & $3.24 \mathrm{ol}$ & $3.23 \mathrm{ol}$ & $3.20 \mathrm{~m}$ & 3.18 dd $(8.9,8.9)$ & $3.23 \mathrm{ol}$ & $3.16 \mathrm{dd}(8.7,8.7)$ \\
\hline 5 & $3.71 \mathrm{~m}$ & $3.69 \mathrm{~m}$ & $3.42 \mathrm{~m}$ & $3.68 \mathrm{~m}$ & $3.70 \mathrm{~m}$ & $3.64 \mathrm{~m}$ \\
\hline $6 \mathrm{a}$ & $4.36 \mathrm{dd}(6.2,11.0)$ & $4.33 \mathrm{dd}(6.2,10.8)$ & $3.70 \mathrm{~m}$ & $4.33 \mathrm{dd}(6.1,11.0)$ & $4.32 \mathrm{dd}(6.1,11.0)$ & $4.31 \mathrm{dd}(6.2,11.0)$ \\
\hline $6 \mathrm{~b}$ & 4.07 br d $(11.0)$ & 4.03 brd $(10.8)$ & 3.46 br d $(11.0)$ & $\mathrm{s} 3 \mathrm{~m}$ & 4.06 brd $(11.0)$ & $3.92 \mathrm{~m}$ \\
\hline \multicolumn{7}{|l|}{ Acyl $\left(\mathrm{R}^{1}\right)$} \\
\hline 2 & $3.32 \mathrm{~s}$ & $3.32 \mathrm{~s}$ & & $3.33 \mathrm{~s}$ & $3.30 \mathrm{~s}$ & $3.30 \mathrm{~s}$ \\
\hline \multicolumn{7}{|l|}{ Acyl $\left(R^{2}\right)$} \\
\hline$\alpha$ & $6.07 \mathrm{~d}(15.8)$ & $6.16 \mathrm{~d}(15.8)$ & $6.21 \mathrm{~d}(15.8)$ & $6.21 \mathrm{~d}(15.8)$ & $6.13 \mathrm{~d}(15.8)$ & $6.22 \mathrm{~d}(15.8)$ \\
\hline$\beta$ & $7.25 \mathrm{~d}(15.8)$ & $7.29 \mathrm{~d}(15.8)$ & $7.32 \mathrm{~d}(15.8)$ & $7.33 \mathrm{~d}(15.8)$ & $7.28 \mathrm{~d}(15.8)$ & $7.33 \mathrm{~d}(15.8)$ \\
\hline 2 & $6.84 \mathrm{~d}(2.1)$ & $7.24 \mathrm{~d}(8.2)$ & $7.04 \mathrm{~s}$ & $7.00 \mathrm{~s}$ & $7.25 \mathrm{~d}(8.2)$ & $7.00 \mathrm{~s}$ \\
\hline 3 & & $6.66 \mathrm{~d}(8.2)$ & & & $6.69 \mathrm{~d}(8.2)$ & \\
\hline 5 & $6.68 \mathrm{~d}(8.2)$ & $6.66 \mathrm{~d}(8.2)$ & $6.73 \mathrm{~d}(8.2)$ & $6.68 \mathrm{~d}(8.2)$ & $6.69 \mathrm{~d}(8.2)$ & $6.69 \mathrm{~d}(8.2)$ \\
\hline 6 & 6.77 dd $(2.1,8.2)$ & $7.24 \mathrm{~d}(8.2)$ & $6.92 \mathrm{~d}(8.2)$ & $6.88 \mathrm{~d}(8.2)$ & $7.25 \mathrm{~d}(8.2)$ & $6.88 \mathrm{~d}(8.2)$ \\
\hline $\mathrm{OMe}$ & & & $3.71 \mathrm{~s}$ & $3.68 \mathrm{~s}$ & & $3.69 \mathrm{~s}$ \\
\hline \multicolumn{7}{|l|}{ Acyl $\left(\mathrm{R}^{3}\right)$} \\
\hline$\alpha$ & $5.87 \mathrm{~d}(15.8)$ & $5.89 \mathrm{~d}(15.8)$ & $5.95 \mathrm{~d}(15.8)$ & $5.89 \mathrm{~d}(15.8)$ & $5.98 \mathrm{~d}(15.8)$ & $6.00 \mathrm{~d}(15.8)$ \\
\hline$\beta$ & $7.14 \mathrm{~d}(15.8)$ & $7.15 \mathrm{~d}(15.8)$ & $7.19 \mathrm{~d}(15.8)$ & $7.15 \mathrm{~d}(15.8)$ & $7.21 \mathrm{~d}(15.8)$ & $7.22 \mathrm{~d}(15.8)$ \\
\hline 2 & $6.83 \mathrm{~d}(2.1)$ & $6.84 \mathrm{~s}$ & $7.23 \mathrm{~d}(8.2)$ & $6.84 \mathrm{~s}$ & $7.24 \mathrm{~d}(8.2)$ & $7.26 \mathrm{~d}(8.2)$ \\
\hline 3 & & & $6.68 \mathrm{~d}(8.2)$ & & $6.67 \mathrm{~d}(8.2)$ & $6.70 \mathrm{~d}(8.2)$ \\
\hline 5 & $6.67 \mathrm{~d}(8.2)$ & $6.68 \mathrm{~d}(8.2)$ & $6.68 \mathrm{~d}(8.2)$ & $6.68 \mathrm{~d}(8.2)$ & $6.67 \mathrm{~d}(8.2)$ & $6.70 \mathrm{~d}(8.2)$ \\
\hline 6 & $6.73 \mathrm{dd}(2.1,8.2)$ & $6.74 \mathrm{~d}(8.2)$ & $7.23 \mathrm{~d}(8.2)$ & $6.75 \mathrm{~d}(8.2)$ & $7.24 \mathrm{~d}(8.2)$ & $7.26 \mathrm{~d}(8.2)$ \\
\hline
\end{tabular}

a) Signals are overlapped.

HMBC correlations of the two pairs of the protons and carbons ( $\mathrm{H}-1$ in Glc-B and C-2 in Glc-A, H-1 in Glc-A and C-3) clarified connectivity of the disaccharide moiety comprised of Glc-A and Glc-B to C-3 in the pelargonidin nucleus. The remaining glucosyl residue (Glc-C) was elucidated to be linked to $\mathrm{C}-5$ in the pelargonidin nucleus by the correlation between $\mathrm{H}-1$ in Glc-C and C-5 in the HMBC spectrum. The same HMBC correlations from the three anomeric protons in 1 appeared with regards to the following five new anthocyanins (2-6), thereby 3-O- $\beta$-D-sophorosyl-5- $O-\beta$-D-glucopyranosylpelargonidin was designated as the common core structure of $\mathbf{1}-\mathbf{6}$.

Additionally, the respective $\mathrm{HMBC}$ correlations from the carbonyl carbons in the caffeoyl groups to H-6 in Glc-A and $\mathrm{H}-6$ in Glc-B definitely settled these acyl functions at $6-\mathrm{OH}$ in Glc-A and 6-OH in Glc-B. The malonyl function was clar- ified to be attached to 6-OH in Glc-C by the HMBC correlation between $\mathrm{H}-6$ in Glc-A and C-1 in Mal. Consequently, the structure of 1 was unequivocally established as 3-O-[6-O(E)-caffeoyl-2-O-\{6-O-(E)-caffeoyl- $\beta$-D-glucopyranosyl $\}-\beta$ D-glucopyranosyl]-5- $O$-(6- $O$-malonyl- $\beta$-D-glucopyranosyl)pelargonidin (Table 2).

The molecular formula of $2(0.012 \%$ from the roots $)$ was determined to be $\mathrm{C}_{54} \mathrm{H}_{55} \mathrm{O}_{28}$ by the FAB-MS and HR-FABMS measurement. Intensive analysis of the $1 \mathrm{D}$ and $2 \mathrm{D}$ NMR data for $\mathbf{2}$ clarified the presence of one malonyl, one $(E)$-caffeoyl, and one $(E)$ - $p$-coumaloyl (Cou) functions as well as the $3-O-\beta$-D-sophorosyl-5- $O-\beta$-D-glucopyranosylpelargonidin core structure. The ${ }^{1} \mathrm{H}$ - and ${ }^{13} \mathrm{C}-\mathrm{NMR}$ spectra of $\mathbf{2}$ fairly resemble those of $\mathbf{1}$ except for the signals derived from the caffeoyl group linked to 6-OH in Glc-A in 1. In the HMBC spectrum of $\mathbf{2}$, the correlation peak was observed between 6 - 
Table 2. ${ }^{13} \mathrm{C}-\mathrm{NMR}$ Data for Anthocyanins $\mathbf{1}-\mathbf{6}(150 \mathrm{MHz}$, DMSO$\left.d_{6}: \mathrm{CF}_{3} \mathrm{COOD}=9: 1\right)$

\begin{tabular}{|c|c|c|c|c|c|c|}
\hline Carbon & 1 & 2 & 3 & 4 & 5 & 6 \\
\hline \multicolumn{7}{|c|}{ Aglycon } \\
\hline 2 & 163.2 & 163.2 & 163.2 & 163.1 & 163.2 & 163.2 \\
\hline 3 & 144.5 & 144.5 & 144.4 & 144.2 & 144.5 & 144.4 \\
\hline 4 & 135.2 & 134.5 & 135.7 & 135.0 & 134.9 & 135.2 \\
\hline $4 a$ & 112.2 & 112.2 & 111.7 & 112.1 & 112.2 & 112.0 \\
\hline 5 & 155.4 & 155.4 & 155.7 & 155.3 & 155.4 & 155.7 \\
\hline 6 & 105.2 & 105.2 & 105.0 & 104.9 & 105.0 & 104.7 \\
\hline 7 & 168.3 & 168.3 & 167.7 & 168.1 & 168.2 & 168.4 \\
\hline 8 & 96.7 & 96.7 & 96.7 & 96.7 & 96.7 & 96.7 \\
\hline $8 \mathrm{a}$ & 155.9 & 155.9 & 155.7 & 155.9 & 155.9 & 155.9 \\
\hline $1^{\prime}$ & 119.5 & 119.5 & 119.7 & 119.5 & 119.5 & 119.5 \\
\hline $2^{\prime}, 6^{\prime}$ & 135.5 & 135.5 & 135.5 & 135.5 & 135.5 & 135.5 \\
\hline $3^{\prime}, 5^{\prime}$ & 117.4 & 111.4 & 117.5 & 117.4 & 117.4 & 116.7 \\
\hline $4^{\prime}$ & 165.7 & 165.7 & 165.7 & 165.7 & 165.7 & 165.7 \\
\hline \multicolumn{7}{|l|}{ Glc-A } \\
\hline 1 & 100.4 & 99.9 & 100.4 & 100.4 & 100.0 & 100.4 \\
\hline 2 & 81.2 & 80.7 & 80.9 & 80.7 & 80.7 & 80.7 \\
\hline 3 & 76.4 & 76.5 & 76.3 & 76.6 & 76.4 & 76.4 \\
\hline 4 & 70.0 & 70.2 & 70.2 & 70.1 & 73.0 & 70.1 \\
\hline 5 & 74.5 & 74.3 & 74.5 & 74.5 & 74.3 & 74.4 \\
\hline 6 & 63.3 & 63.3 & 63.2 & 63.5 & 63.2 & 63.3 \\
\hline \multicolumn{7}{|l|}{ Glc-B } \\
\hline 1 & 104.5 & 104.3 & 104.2 & 104.4 & 104.4 & 104.2 \\
\hline 2 & 74.9 & 74.9 & 74.8 & 75.2 & 75.4 & 74.8 \\
\hline 3 & 76.5 & 76.4 & 76.7 & 76.5 & 76.5 & 76.5 \\
\hline 4 & 70.0 & 69.8 & 70.0 & 70.0 & 69.7 & 70.1 \\
\hline 5 & 74.5 & 74.5 & 74.2 & 74.5 & 74.4 & 74.4 \\
\hline 6 & 63.2 & 63.1 & 63.2 & 63.3 & 63.5 & 63.2 \\
\hline \multicolumn{7}{|l|}{ Glc-C } \\
\hline 1 & 101.7 & 102.0 & 101.7 & 101.9 & 101.8 & 101.7 \\
\hline 2 & 73.5 & 73.4 & 73.7 & 73.6 & 73.4 & 73.4 \\
\hline 3 & 76.3 & 76.2 & 76.7 & 76.6 & 76.0 & 76.1 \\
\hline 4 & 70.0 & 69.8 & 70.0 & 70.0 & 70.0 & 70.1 \\
\hline 5 & 74.6 & 74.5 & 78.2 & 74.6 & 74.4 & 74.5 \\
\hline 6 & 64.3 & 64.2 & 60.9 & 64.6 & 63.2 & 64.5 \\
\hline \multicolumn{7}{|c|}{$\operatorname{Acyl}\left(\mathrm{R}^{1}\right)$} \\
\hline 1 & 166.9 & 167.0 & & 166.8 & 167.0 & 167.1 \\
\hline 2 & 41.7 & 41.4 & & 41.6 & 41.6 & 41.5 \\
\hline 3 & 167.7 & 167.9 & & 167.8 & 167.9 & 168.0 \\
\hline \multicolumn{7}{|c|}{ Acyl $\left(\mathrm{R}^{2}\right)$} \\
\hline $\mathrm{CO}$ & 166.9 & 166.7 & 167.0 & 167.1 & 166.9 & 167.1 \\
\hline$\alpha$ & 114.0 & 114.0 & 114.4 & 114.0 & 114.0 & 114.3 \\
\hline$\beta$ & 145.8 & 145.4 & 145.8 & 145.8 & 145.8 & 145.0 \\
\hline 1 & 125.7 & 125.7 & 125.7 & 125.7 & 125.7 & 125.7 \\
\hline 2 & 115.5 & 130.7 & 111.9 & 111.7 & 130.7 & 111.7 \\
\hline 3 & 145.7 & 116.0 & 147.9 & 148.1 & 116.0 & 147.7 \\
\hline 4 & 148.7 & 160.1 & 149.7 & 149.7 & 160.2 & 148.8 \\
\hline 5 & 116.1 & 116.0 & 115.9 & 116.1 & 116.0 & 116.1 \\
\hline 6 & 121.3 & 130.7 & 123.4 & 123.1 & 130.7 & 123.3 \\
\hline $\mathrm{OMe}$ & & & 56.0 & 55.7 & & 56.0 \\
\hline \multicolumn{7}{|c|}{ Acyl $\left(R^{3}\right)$} \\
\hline $\mathrm{CO}$ & 166.7 & 167.1 & 166.7 & 166.7 & 166.7 & 166.7 \\
\hline$\alpha$ & 114.0 & 114.0 & 114.0 & 114.0 & 114.0 & 114.1 \\
\hline$\beta$ & 145.5 & 145.4 & 144.9 & 145.6 & 145.6 & 145.7 \\
\hline 1 & 125.7 & 125.7 & 125.7 & 125.7 & 125.7 & 125.7 \\
\hline 2 & 115.3 & 115.3 & 130.6 & 115.2 & 130.5 & 130.5 \\
\hline 3 & 145.7 & 145.7 & 116.7 & 145.7 & 116.1 & 116.1 \\
\hline 4 & 148.7 & 148.7 & 160.2 & 148.8 & 159.9 & 159.7 \\
\hline 5 & 115.9 & 116.0 & 116.7 & 116.1 & 116.1 & 116.1 \\
\hline 6 & 121.5 & 121.6 & 130.6 & 121.7 & 130.5 & 130.5 \\
\hline
\end{tabular}

$\mathrm{H}$ in Glc-A and the carbonyl resonance of the $p$-coumaroyl group. In addition to this correlation, the HMBC correlations were confirmed in the same pairs of the protons in the sugar residues and the other carbonyl carbons as detected in the $\mathrm{HMBC}$ spectrum of $\mathbf{1}$. Hence, the anthocyanin ingredient
2 was unambiguously revealed to be 3-O-[6-O- $(E)-p$ coumaroyl-2-O-\{6-O-(E)-caffeoyl- $\beta$-D-glucopyranosyl $\}-\beta$-Dglucopyranosyl]-5-O-(6-O-malonyl- $\beta$-D-glucopyranosyl)pelargonidin.

Based on the FAB-MS and HR-FAB-MS data, compound $3(0.0034 \%$ from the roots) was shown to possess the molecular formula of $\mathrm{C}_{52} \mathrm{H}_{55} \mathrm{O}_{25}$. Comparison of the ${ }^{1} \mathrm{H}$ - and ${ }^{13} \mathrm{C}$ NMR spectra of $\mathbf{3}$ with those of the above-mentioned two anthocyanins $(\mathbf{1}, \mathbf{2})$ clarified lack of a malonyl group. The presence of both $(E)$-feruloyl and $(E)$-p-coumaroyl functions was disclosed along with the 3- $O-\beta$-D-sophorosyl-5- $O$ - $\beta$-D-glucopyranosylpelargonidin core by detailed analysis of the NMR data for $\mathbf{3}$. The HMBC spectrum of $\mathbf{3}$ exhibited the cross peaks from H-6 in Glc-A to the carbonyl carbon in the feruloyl group and from H-6 in Glc-B to the carbonyl carbon in the $p$-coumaroyl group. Taking these spectral features into account, the structure of 3 was established as 3-O-[6-O- $(E)$ feruloyl-2-O-\{6-O-(E)-p-coumaroyl- $\beta$-D-glucopyranosyl $\}-\beta$ D-glucopyranosyl]-5- $O$ - $\beta$-D-glucopyranosylpelargonidin.

The FAB-MS spectra of 4 (0.028\% from the roots) exhibited the molecular ion peak at $1181\left[\mathrm{M}^{+}\right.$, while the molecular formula $\mathrm{C}_{55} \mathrm{H}_{57} \mathrm{O}_{29}$ was determined by the HR-FAB-MS measurement. The ${ }^{1} \mathrm{H}$ - and ${ }^{13} \mathrm{C}$-NMR spectra are superimposable on those of $\mathbf{1}$ except for the signals due to the caffeoyl group at 6-OH in Glc-A of 1 . By comparison of the NMR and MS data of 4 with those of $\mathbf{1}$, the (E)-feruloyl group was deduced to be linked to 6-OH in Glc-A of 4 instead of the caffeoyl group of 1. Furthermore, the HMBC correlations were observed in the following pairs of the protons and the carbons (H-6 in Glc-A and the carbonyl carbon in Fer, H-6 in Glc-B and the carbonyl carbon in Caf, H-6 in Glc-C and C-1 in Mal). Therefore, the anthocyanin 4 was revealed to be 3-O-[6-O-(E)-feruloyl-2-O-\{6-O-(E)-caffeoyl- $\beta$ D-glucopyranosyl $\}$ - $\beta$-D-glucopyranosyl]-5- $O$-(6- $O$-malonyl- $\beta$ D-glucopyranosyl)pelargonidin.

From the the FAB-MS and HR-FAB-MS data, the molecular formula of $5(0.0071 \%$ from the roots $)$ was determined to be $\mathrm{C}_{54} \mathrm{H}_{55} \mathrm{O}_{27}$. On the basis of the NMR data, compound $\mathbf{5}$ was revealed to possess one malonyl and two $(E)-p$ coumaroyl functions along with the core $3-O-\beta$-D-sophorosyl-5- $O-\beta$-D-glucopyranosylpelargonidin. The HMBC spectrum of $\mathbf{5}$ displayed the correlations from H-6 in Glc-A to the carbonyl carbon in Cou, from H-6 in Glc-B to the carbonyl carbon in $\mathrm{Cou}$, and from $\mathrm{H}-6$ in Glc-C to $\mathrm{C}-1$ in Mal. These spectroscopic properties unequivocally constructed the structure of 3-O-[6-O-(E)- $p$-coumaroyl-2-O- $\{6-O-(E)-p$-coumaroyl$\beta$-D-glucopyranosyl $\}-\beta$-D-glucopyranosyl]-5- $O$-(6- $O$-malonyl$\beta$-D-glucopyranosyl)pelargonidin for $\mathbf{5}$.

The molecular formula of $6(0.0056 \%$ from the roots $)$ was determined to be $\mathrm{C}_{55} \mathrm{H}_{57} \mathrm{O}_{28}$ by the FAB-MS and HR-FABMS analysis. The NMR data for 6 revealed the presence of one (E)-feruloyl, one (E)-p-coumaroyl, and one malonyl functionalities. In the HMBC experiment, the correlations were detected in the following pairs of the protons and carbons (H-6 in Glc-A and the carbonyl carbon in Fer, H-6 in Glc-B and the carbonyl carbon in Cou, H-6 in Glc-C and C-1 in Mal). As a result of comprehensive examination of these spectroscopic data, the anthocyanin 6 was elucidated to be 3 $O$-[6-O- $(E)$-feruloyl-2- $O$ - $\{6-O-(E)-p$-coumaroyl- $\beta$-D-glucopyranosyl $\}-\beta$-D-glucopyranosyl]-5- $O$-(6- $O$-malonyl- $\beta$-D-glucopyranosyl)pelargonidin. 
In conclusion, we disclosed the six new acylated anthocyanins (1-6) along with the three known congeners (7-9) from the fresh roots of red radishes cultivated by our group. Among them, the eight ingredients except for $\mathbf{3}$ were shown to contain the malonyl function at $6-\mathrm{OH}$ in the glucopyranosyl residue linked to $\mathrm{C}-5$ in the pelargonidin nucleus. Previously, the relative malonylated anthocyanins were isolated from the other red radishes, Raphanus sativus cv. Beijing hong xin and were found to overwhelmingly possess $(E)$-feruloyl function in Glc-A and Glc-B. ${ }^{12)}$ On the contrary, the red radishes used in the present investigation were shown to produce the anthocyanins including (E)-feruloyl, $(E)$-p-coumaroyl, and $(E)$-caffeoyl functionalities on the average. This finding suggests that these two red radishes may possess different process to generate and/or acylate the three phenylpropanoic carboxylic acids.

\section{Experimental}

General Experimental Procedures ${ }^{1} \mathrm{H}$ - and ${ }^{13} \mathrm{C}-\mathrm{NMR}$, and 2D-MNR spectra were recorded on a Varian Unity Inova $600(600 \mathrm{MHz})$ spectrometer. All NMR data were referenced to a tetramethylsilane (TMS) internal standard, and chemical shifts are expressed in $\delta$ ppm. IR spectra were recorded on a JASCO FT/IR-5300 infrared spectrometer. FAB-MS and HR-FAB-MS data were acquired on a JEOL JMS-HX 110/110A mass spectrometer. UV spectra were measured on a Shimadzu UVmini-1200 spectrophotometer HPLC was performed on a JASCO PU2080 pump equipped with a JASCO UV2070 UV detector.

Plant Material The used red radishes were introduced from Yunnan province of China to Japan in 1996 by San-Ei Gen F. F. I. Inc. Cultivation of red radishes was conducted at the field in the Botanical Garden belonging to Graduate School of Pharmaceutical Sciences of Osaka University.

Extraction and Isolation The fresh roots of the red radishes $(2.0 \mathrm{~kg})$ were cut into $c a$. $1 \mathrm{~cm}$ cubes, then the cubes were extracted with $5 \%$ aqueous citric acid at room temperature for $6 \mathrm{~h}$ for three times. After filtration, the combined filtrate was absorbed on a Diaion HP-20 (Mitsubishi Chemical, Japan) column. Then the column was successively eluted by $0.1 \%$ aqueous trifluoroacetic acid (TFA) and $70 \%$ aqueous $\mathrm{CH}_{3} \mathrm{CN}$ containing $0.1 \%$ TFA. The $70 \%$ aqueous $\mathrm{CH}_{3} \mathrm{CN}$ eluent was evaporated in vacuo to give a crude mixture of anthocyanins $(18.9 \mathrm{~g})$. An aliquot of the crude anthocyanin mixture $(2.5 \mathrm{~g})$ was repeatedly separated by HPLC (column: Develosil C30-UG $20 \times 250 \mathrm{~mm}$, flow rate: $9.0 \mathrm{ml}$, mobile phase: $\mathrm{CH}_{3} \mathrm{CN}: \mathrm{H}_{2} \mathrm{O}: \mathrm{TFA}=$ $21: 79: 0.1$, detection: $515 \mathrm{~nm})$ to provide fr. $1(44.3 \mathrm{mg})$, fr. $2(115.0 \mathrm{mg})$ fr. $3(155.2 \mathrm{mg})$, fr. $4(95.4 \mathrm{mg})$, fr. $5(122.0 \mathrm{mg})$, fr. $6(168.5 \mathrm{mg})$, fr. 7 $(85.2 \mathrm{mg})$, fr. $8(64.7 \mathrm{mg})$, fr. $9(106.0 \mathrm{mg})$, fr. $10(46.2 \mathrm{mg})$, fr. 11 $(130.8 \mathrm{mg})$, fr. $12(30.4 \mathrm{mg})$, respectively.

Fr. $2(50 \mathrm{mg})$ was purified by HPLC (column: Supelcosil LC-ABZ $10 \times 250 \mathrm{~mm}$, flow rate: $4.0 \mathrm{ml}$, mobile phase: $\mathrm{CH}_{3} \mathrm{CN}: \mathrm{H}_{2} \mathrm{O}: \mathrm{TFA}=$ $22: 78: 0.1$, detection: $515 \mathrm{~nm})$ to give $7(10.4 \mathrm{mg})$. Fr. $3(60 \mathrm{mg})$ was purified by HPLC (column: Supelcosil LC-ABZ $10 \times 250 \mathrm{~mm}$, flow rate: $4.0 \mathrm{ml}$, mobile phase: $\mathrm{CH}_{3} \mathrm{CN}-\mathrm{H}_{2} \mathrm{O}-\mathrm{AcOH}=8: 77: 15$, detection: $515 \mathrm{~nm}$ ) to give 1 $(14.8 \mathrm{mg})$. Fr. $5(50 \mathrm{mg})$ was purified by HPLC (column: Supelcosil LCABZ $10 \times 250 \mathrm{~mm}$, flow rate: $4.0 \mathrm{ml}$, mobile phase: $\mathrm{CH}_{3} \mathrm{CN}-\mathrm{H}_{2} \mathrm{O}-\mathrm{AcOH}=$ $12: 73: 15$, detection: $515 \mathrm{~nm})$ to give $8(6.2 \mathrm{mg})$. Fr. $6(50 \mathrm{mg})$ was purified by HPLC (column: Supelcosil LC-ABZ $10 \times 250 \mathrm{~mm}$, flow rate: $4.0 \mathrm{ml}$, mobile phase: $\mathrm{CH}_{3} \mathrm{CN}-\mathrm{H}_{2} \mathrm{O}-\mathrm{AcOH}=12: 73: 15$, detection: $515 \mathrm{~nm}$ ) to give 9 $(8.7 \mathrm{mg})$. Fr. $8(50 \mathrm{mg})$ was purified by HPLC (column: Supelcosil RPAMIDE $10 \times 250 \mathrm{~mm}$, flow rate: $4.0 \mathrm{ml}$, mobile phase: $\mathrm{CH}_{3} \mathrm{CN}-\mathrm{H}_{2} \mathrm{O}$ $\mathrm{AcOH}=12: 73: 15$, detection: $515 \mathrm{~nm})$ to give $2(24.5 \mathrm{mg})$ and $3(7.0 \mathrm{mg})$ Fr. $9(50.0 \mathrm{mg}$ ) was purified by HPLC (column: Cosmosil 5C18-AR-II $10 \times 250 \mathrm{~mm}$, flow rate: $4.0 \mathrm{ml}$, mobile phase: $\mathrm{CH}_{3} \mathrm{CN}-\mathrm{H}_{2} \mathrm{O}-\mathrm{AcOH}=$ $14: 71: 15$, detection: $515 \mathrm{~nm})$ to give $4(34.5 \mathrm{mg})$. Fr. $11(50 \mathrm{mg})$ was puri- fied by HPLC (column: Supelcosil LC-ABZ $10 \times 250 \mathrm{~mm}$, flow rate: $4.0 \mathrm{ml}$, mobile phase: $\mathrm{CH}_{3} \mathrm{CN}: \mathrm{H}_{2} \mathrm{O}:$ TFA $=26: 74: 0.1$, detection: $515 \mathrm{~nm}$ ) to give 5 (7.2 mg). Fr. $12(30.4 \mathrm{mg}$ ) was purified by HPLC (column: Supelcosil LCABZ $10 \times 250 \mathrm{~mm}$, flow rate: $4.0 \mathrm{ml}$, mobile phase: $\mathrm{CH}_{3} \mathrm{CN}: \mathrm{H}_{2} \mathrm{O}: \mathrm{TFA}=$ $26: 74: 0.1$, detection: $515 \mathrm{~nm})$ to give $6(14.7 \mathrm{mg})$.

1: A purple amorphous powder. IR $(\mathrm{KBr}) \mathrm{cm}^{-1}: 3300,1718(\mathrm{sh}), 1685$, 1641,1607 . UV $\lambda_{\max }\left(0.1 \%\right.$ TFA- $\left.\mathrm{H}_{2} \mathrm{O}\right) \mathrm{nm}(\varepsilon): 518$ (18400), 328 (24300), 287 (22000). FAB-MS $m / z$ : $1167\left(\right.$ M $^{+}$. HR-FAB-MS m/z: 1167.2826 (Calcd for $\left.\mathrm{C}_{54} \mathrm{H}_{55} \mathrm{O}_{29}: 1167.2829\right)$. ${ }^{1} \mathrm{H}$ - and ${ }^{13} \mathrm{C}-\mathrm{NMR}$ : see Tables 1 and 2.

2: A purple amorphous powder. IR (KBr) $\mathrm{cm}^{-1}: 3300,1716(\mathrm{sh}), 1686$, 1643, 1606. UV $\lambda_{\max }\left(0.1 \% \mathrm{TFA}-\mathrm{H}_{2} \mathrm{O}\right) \mathrm{nm}(\varepsilon): 517$ (18000), 318 (24200), 288 (21400). FAB-MS $m / z: 1151$ (M) ${ }^{+}$. HR-FAB-MS $m / z: 1151.2875$ (Calcd for $\left.\mathrm{C}_{54} \mathrm{H}_{55} \mathrm{O}_{28}: 1151.2880\right)$. ${ }^{1} \mathrm{H}$ - and ${ }^{13} \mathrm{C}-\mathrm{NMR}$ : see Tables 1 and 2 .

3: A purple amorphous powder. IR $(\mathrm{KBr}) \mathrm{cm}^{-1}: 3300,1685,1642,1612$. UV $\lambda_{\text {max }}\left(0.1 \%\right.$ TFA- $\left.\mathrm{H}_{2} \mathrm{O}\right) \mathrm{nm}(\varepsilon): 516$ (18000), 321 (24000), 285 (21600). FAB-MS $m / z: 1079(\mathrm{M})^{+}$. HR-FAB-MS m/z: 1079.3025 (Calcd for $\mathrm{C}_{52} \mathrm{H}_{55} \mathrm{O}_{25}:$ 1079.3032). ${ }^{1} \mathrm{H}$ - and ${ }^{13} \mathrm{C}-\mathrm{NMR}$ : see Tables 1 and 2.

4: A purple amorphous powder. IR $(\mathrm{KBr}) \mathrm{cm}^{-1}: 3300,1715(\mathrm{sh}), 1685$, 1641,1604 . UV $\lambda_{\max }\left(0.1 \%\right.$ TFA- $\left.\mathrm{H}_{2} \mathrm{O}\right) \mathrm{nm}(\varepsilon): 519$ (18600), 329 (24700), 286 (20600). FAB-MS $m / z$ : 1181 (M) ${ }^{+}$. HR-FAB-MS $m / z$ : 1181.2988 (Calcd for $\left.\mathrm{C}_{55} \mathrm{H}_{57} \mathrm{O}_{29}: 1181.2986\right) .{ }^{1} \mathrm{H}$ - and ${ }^{13} \mathrm{C}$-NMR: see Tables 1 and 2.

5: A purple amorphous powder. IR $(\mathrm{KBr}) \mathrm{cm}^{-1}: 3300,1717(\mathrm{sh}), 1688$, 1649,1600 . UV $\lambda_{\text {max }}\left(0.1 \%\right.$ TFA-H $\left.H_{2} \mathrm{O}\right) \mathrm{nm}(\varepsilon): 515$ (19200), 317 (25100), 288 (22000). FAB-MS $m / z: 1135(\mathrm{M})^{+}$. HR-FAB-MS m/z: 1181.2930 (Calcd for $\mathrm{C}_{54} \mathrm{H}_{55} \mathrm{O}_{27}$ : 1135.2931). ${ }^{1} \mathrm{H}$ - and ${ }^{13} \mathrm{C}-\mathrm{NMR}$ : see Tables 1 and 2.

6: A purple amorphous powder. IR (KBr) $\mathrm{cm}^{-1}: 3300,1713(\mathrm{sh}), 1683$, 1643,1605 . UV $\lambda_{\max }\left(0.1 \%\right.$ TFA- $\left.\mathrm{H}_{2} \mathrm{O}\right) \mathrm{nm}(\varepsilon): 517$ (18500), 320 (24500), 286 (21700). FAB-MS $m / z$ : $1165(\mathrm{M})^{+}$. HR-FAB-MS m/z: 1165.3034 (Calcd for $\left.\mathrm{C}_{55} \mathrm{H}_{57} \mathrm{O}_{28}: 1165.3036\right) .{ }^{1} \mathrm{H}$ - and ${ }^{13} \mathrm{C}-\mathrm{NMR}$ : see Tables 1 and 2 .

Acknowledgments This work was supported in part by Research Grants from San-Ei Gen F. F. I. Inc. The authors are grateful to the Japan Food Chemical Research Foundation for financial support.

\section{References}

1) Pascual S., Sanchez T. M., Phytochem. Rev., 7, 281-299 (2008).

2) Shimizu T., Kawahara A., Nakamura M., Kato Y., Goda Y., Maitani T., Jpn. J. Food Chem., 3, 10-20 (1996)

3) Hrazdina G., Iredale H., Mattick L. R., Phytochemistry, 16, 297—299 (1977).

4) Odake K., Terahara N., Saito N., Toki K., Honda T., Phytochemistry, 31, 2127-2130 (1992).

5) Goda Y., Shimizu T., Kato Y., Nakamura M., Maitani T., Yamada T., Terahara N., Yamaguchi M., Phytochemistry, 44, 183-186 (1997).

6) Terahara N., Shimizu T., Kato Y., Nakamura M., Maitani T., Yamaguchi M., Goda Y., Biosci. Biotechnol. Biochem., 63, 1420-1424 (1999).

7) Cabrita L., Andersen O. M., Phytochemistry, 52, 1693-1696 (1999).

8) Johansen O., Anderson Ø̃., Nerdal W., Aksnes D., Phytochemistry, 30, 4137-4141 (1991)

9) Nakatani N., Kikuzaki H., Hikida J., Ohba M., Inami O., Tamura I., Phytochemistry, 38, 755-757 (1995).

10) Otsuki T., Matsufuji H., Takeda M., Toyoda M., Goda Y., Phytochemistry, 60, 79-87 (2002).

11) Guisti M. M., Ghanadan H., Wrolstad R. E., J. Agric. Food Chem., 46, 4858-4863 (1998).

12) Mori M., Nakagawa S., Maeshima M., Niikura S., Yoshida K., Heterocycles, 69, 239-251 (2006).

13) Fujii M., Shimizu T., Nakamura M., "Syokuyou Tennensikiso," Korin, Tokyo, 2001.

14) Tsuji K., Ohno T., Murakami N., Jpn. J. Food Chem., 11, 151-154 (2004).

15) Tatsuzawa F., Toki K., Saito N., Shinoda K., Shigihara A., Honda T., Dyes and Pigments, 79, 83-88 (2008). 